\title{
Saline-induced $\mathrm{Pd} / \mathrm{Pa}$ ratio predicts functional significance of coronary stenosis assessed using fractional flow reserve
}

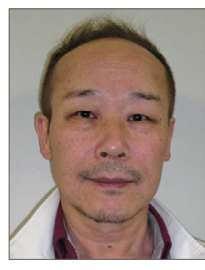

Yoshiharu Fujimori ${ }^{1 *}$, MD; Tomoko Babaํ, MD; Kyohei Yamazaki², MD; Satoshi Hashimoto ${ }^{1}$, MD; Yasushi Yamanaka ${ }^{1}$, MD; Kenichiro Ebisuda ${ }^{1}$, MD; Kazuto Kurihara ${ }^{1}$, MD; Naoki Koike ${ }^{2}$, MD; Nao Takeuchi ${ }^{1}$, MD; Shigeru Nishiyama ${ }^{1}$, MD; Yuya Terasawa ${ }^{1}, \mathrm{CE}$; Tadamasa Wakabayashi ${ }^{1}, \mathrm{MD}$; Taku Imai ${ }^{1}, \mathrm{MD}$

1. Department of Cardiology, Suwa Central Hospital, Chino, Japan; 2. Department of Cardiology, Showa Inan General Hospital, Komagane, Japan

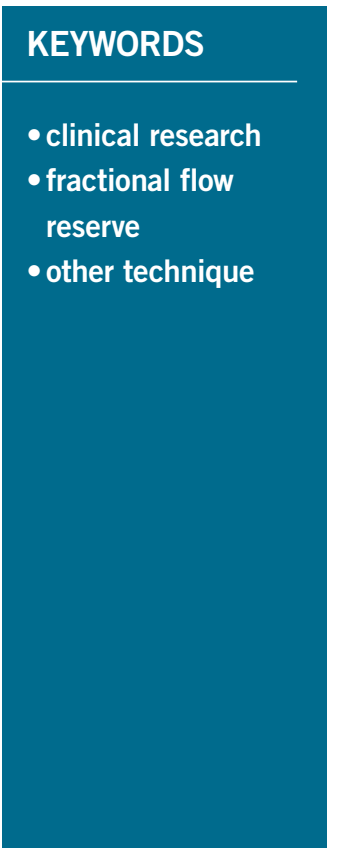

\begin{abstract}
Aims: Fractional flow reserve (FFR), assessed using distal coronary pressure/aortic pressure $(\mathrm{Pd}) /(\mathrm{Pa})$ ratio, functionally evaluates coronary stenosis. An assessment method without vasodilators would be helpful. A single intracoronary bolus of saline decreases Pd because of the speculated low-viscosity effect. We hypothesised that saline-induced $\mathrm{Pd} / \mathrm{Pa}$ ratio (SPR) could functionally evaluate coronary stenosis. This study aimed to test the accuracy and utility of SPR for predicting FFR $\leq 0.80$.
\end{abstract}

Methods and results: In 137 coronary lesions with over 50\% angiographic diameter stenosis, SPR was assessed using an intracoronary bolus of saline $(2 \mathrm{~mL} / \mathrm{s})$ for five heartbeats (SPR-5) and three heartbeats (SPR-3). FFR was obtained after intravenous adenosine infusion $(140 \mu \mathrm{g} / \mathrm{kg} / \mathrm{min})$. There was a strong correlation between FFR and SPR- 5 or SPR-3 ( $\mathrm{R}=0.941$ and $\mathrm{R}=0.933$, respectively). Receiver operating characteristic (ROC) curve analysis demonstrated good accuracy (86.3\%) for SPR-5, with a cut-off of $\leq 0.84$ for predicting FFR $\leq 0.80$ (area under ROC curve 0.96 , specificity 94.3 , sensitivity 79.9 ). Thirty-three lesions (24\%) were located in the "grey zone" (SPR 0.83-0.88). No complications were observed in 673 SPR measurements.

Conclusions: SPR may accurately predict FFR and can limit adenosine use to one in four lesions. Further studies are needed to confirm the validity of SPR.

\footnotetext{
*Corresponding author: Department of Cardiology, Suwa Central Hospital, 4300 Tamagawa, Chino, 391-8503, Japan. E-mail: fujimori.yoshiharu@gmail.com
} 


$\begin{array}{ll}\text { Abbreviations } \\ \text { AUC } & \text { area under the curve } \\ \text { CI } & \text { confidence interval } \\ \text { CFFR } & \text { contrast fractional flow reserve } \\ \text { FFR } & \text { fractional flow reserve } \\ \text { ICC } & \text { intraclass correlation coefficients } \\ \text { iFR } & \text { instantaneous wave-free ratio } \\ \text { NPV } & \text { negative predictive value } \\ \text { PCI } & \text { percutaneous coronary intervention } \\ \text { Pd/Pa } & \text { distal coronary pressure/aortic pressure } \\ \text { PPV } & \text { positive predictive value } \\ \text { ROC } & \text { receiver operating characteristic } \\ \text { SD } & \text { standard deviation } \\ \text { SPR } & \text { saline-induced } \mathrm{Pd} / \mathrm{Pa} \text { ratio }\end{array}$

\section{Introduction}

In the last decade, the importance of functional assessment of coronary stenosis by fractional flow reserve (FFR) using distal coronary pressure/aortic pressure $(\mathrm{Pd} / \mathrm{Pa})$ ratio, instantaneous wave-free ratio (iFR), and resting $\mathrm{Pd} / \mathrm{Pa}$ has come to light. Several studies have demonstrated improvement in patient outcomes, allowing more appropriate selection of lesions for percutaneous coronary intervention $(\mathrm{PCI})^{1,2}$. These assessments have been incorporated into PCI guidelines ${ }^{3,4}$; nevertheless, these assessments are still underused. To achieve maximal hyperaemia for FFR assessment, intravenous administration or intracoronary high-dose bolus of adenosine has been employed ${ }^{5-7}$. However, completion of one FFR measurement using intravenous infusion of adenosine requires 4 to $5 \mathrm{~min}$, and intracoronary bolus of adenosine has some potential drawbacks ${ }^{5-8}$.

Leone et $\mathrm{al}^{9}$ and Johnson et $\mathrm{al}^{10}$ have reported a high accuracy for predicting FFR $\leq 0.80$ using contrast FFR (cFFR). cFFR is based on vasodilation-mediated hyperaemia induced by the high osmolality of contrast medium ${ }^{9-11}$. However, cFFR has a limitation resulting from the heterogeneity of osmolality among contrast media9, ${ }^{9}$, and the dose of contrast media itself is limited.

As an alternative to assessments using vasodilators or contrast media, we focused on blood viscosity. A fluid with lower viscosity can flow through arterioles at a higher rate ${ }^{12}$, resulting in its rapid exit from the arterioles to the venous system and decreased Pd. The blood flow through small vessels is inversely proportional to wholeblood viscosity ${ }^{12}$, which is affected by volume (haematocrit) ${ }^{13}$, deformation $^{14}$ and aggregation of red blood cells ${ }^{15}$, and plasma viscosity ${ }^{16}$. The viscosities of whole blood at $37^{\circ} \mathrm{C}$ and saline are 4.0-4.5 and $1.012 \mathrm{mPa} \cdot \mathrm{s}$, respectively ${ }^{12-16}$. We selected saline as a low-viscosity fluid and hypothesised that we could substitute saline-induced $\mathrm{Pd} /$ Pa ratio (SPR) for FFR. This study was conducted to test the accuracy and utility of SPR for predicting FFR $\leq 0.80$.

\section{Editorial, see page 849}

\section{Methods \\ PATIENT POPULATION}

Among patients undergoing cardiac catheterisation, those who underwent FFR assessment were enrolled. The inclusion criterion was a stenotic coronary lesion with over $50 \%$ angiographic diameter stenosis on visual estimation. Exclusion criteria were: 1) ostial stenosis in both the left and right coronary arteries, 2) tandem lesions, 3) acute myocardial infarction within the preceding two weeks, 4) severe valvular heart disease, 5) decompensated congestive heart failure, 6) extreme hypotension (systolic blood pressure $<100 \mathrm{mmHg}$ ) and extreme bradycardia $(<40 \mathrm{bpm})$. The study was approved by local ethics committees and conformed to the Declaration of Helsinki on human research. The study was registered with the UMIN clinical trials registry (UMIN000021357). All patients provided written informed consent after the protocol and potential risks were explained.

\section{CORONARY ANGIOGRAPHY}

Coronary angiography was performed using a 4 Fr, 5 Fr diagnostic, or $6 \mathrm{Fr}$ guiding catheter. We intravenously administered $100 \mathrm{IU} / \mathrm{kg}$ of heparin prior to coronary angiography. We used a non-ionic contrast medium (Iopamiron ${ }^{\circledR}$; Bracco, Milan, Italy). Three experienced cardiologists visually assessed the severity of coronary stenosis.

\section{PRESSURE MEASUREMENTS}

After calibration and equalisation of a 0.014 -inch pressure guidewire (Certus ${ }^{\mathrm{TM}}$ and Aeris ${ }^{\mathrm{TM}}$; St. Jude Medical/Abbott, St. Paul, $\mathrm{MN}$, USA), we administered intracoronary nitrates and advanced the wire distally.

The study consisted of two sequential steps:

1. SPR assessment: we administered an intracoronary bolus of saline at room temperature at $2 \mathrm{~mL} / \mathrm{second}$ through the catheter using a power injector system (ACIST ${ }^{\circledR}$; ACIST Medical Systems, Eden Prairie, MN, USA). SPR was calculated as $\mathrm{Pd} / \mathrm{Pa}$ ratio after intracoronary saline injection. We defined the $\mathrm{Pd} / \mathrm{Pa}$ value at the inflection point between rapid increase and plateau as the SPR value. To set the optimal duration of saline injection, we injected saline for five heartbeats (SPR-5) and three heartbeats (SPR-3).

2. FFR assessment: after intravenous infusion of adenosine (140 $\mu \mathrm{g} / \mathrm{kg} / \mathrm{min}$ ), FFR was assessed during peak hyperaemia. To test the relationship between the saline effect and arteriolar diameter, we added an intracoronary bolus of saline for five heartbeats during FFR recording (FFR+saline).

To test reproducibility, we sequentially repeated every saline injection twice. Haemodynamic parameters were continuously recorded periprocedurally. We observed the patients' symptoms and complications. Clinical features, coronary risk factors, left ventricular function, and medications were recorded. All patients continued their medications before and during examinations.

\section{STATISTICAL ANALYSIS}

Categorical variables were expressed as percentages and analysed using Fisher's exact test. Continuous variables were expressed as means \pm SDs (standard deviations) and compared using the t-test, paired t-test, or parametric Wilcoxon test, as appropriate. 
We quantified the relationship between SPRs and FFR using the coefficient of determination ( $\mathrm{R}$ or $\mathrm{R}^{2}$ ). The validity of lesionlevel analysis according to the assumption of independence was evaluated using intraclass correlation coefficients (ICCs) of oneway random effects models for the main variables, SPRs and FFR. We analysed the agreement between SPR and FFR using Bland-Altman plots and 95\% limits of agreement. We examined the performance of SPR for predicting FFR $\leq 0.80$ using sensitivity, specificity, positive predictive value (PPV), negative predictive value (NPV), and diagnostic accuracy, with 95\% confidence intervals (CIs). The receiver operating characteristic (ROC) curve was used to measure the accuracy via area under the curve (AUC) and to identify the optimal SPR cut-off for predicting FFR $\leq 0.80$. All statistical analyses were performed using MedCalc (MedCalc Software, Mariakerke, Belgium) and SPSS, Version 23.0 (IBM Japan, Ltd., Tokyo, Japan). FFR $\leq 0.80$ was considered as an indication for PCI. A p-value $<0.05$ was considered significant.

To limit the use of adenosine to achieve at least $95 \%$ safety, we defined the equivocal SPR values as the "grey zone", identifying the lower cut-off as the lowest SPR value with 95\% specificity for FFR $\leq 0.80$ and the upper cut-off as the lowest SPR value with $95 \%$ sensitivity for FFR $\leq 0.80$. As in the previous studies ${ }^{9,10}$, we maximised the diagnostic accuracy using these cut-off values, limiting the use of adenosine for FFR assessment to the grey zone (hybrid approach).

In verifying the main objective of this study that "FFR $\leq 0.80$ can be predicted with SPR", the AUC calculated by ROC analysis was assumed to be 0.95 , and a $95 \%$ CI of \pm 0.05 was required as the accuracy of the AUC. In the above setting, as a result of the power calculation, the required sample size was 105 lesions. After that, 137 lesions were taken as the final sample size, considering the occurrence of missing values and prediction error.

\section{Results \\ BASELINE CHARACTERISTICS}

From August 2015 to June 2017, we enrolled 137 (105 patients) of 152 lesions assessed by FFR, according to the inclusion and exclusion criteria. The characteristics of the study population are listed in Table 1. The target arteries were the left anterior descending $(55.7 \%)$, right coronary $(26.3 \%)$, and left circumflex $(18.2 \%)$ arteries. Multivessel disease was found in 33 (31\%) cases. SPR-5 and FFR measurements were completed in 137 lesions and SPR-3 in 112. As a result of calculating the ICC for SPR-5 and FFR in cases using data of multiple lesions, correlation within the case was found to be low (SPR-5: ICC $=0.186$ [95\% CI: $-0.205,0.527]$, $\mathrm{p}=0.173$; FFR: ICC $=0.055$ [95\% CI: $-0.328,0.425], \mathrm{p}=0.391$ ). The validity of analysing the lesion level under the assumption of independence was proved.

\section{CORRELATION BETWEEN SPRS AND FFR, AND ACCURACY OF SPR FOR PREDICTING FFR}

The mean value of resting $\mathrm{Pd} / \mathrm{Pa}$ was $0.91 \pm 0.11$ (Figure 1). The mean values of SPR-5 and SPR-3 were $0.85 \pm 0.12$ and $0.86 \pm 0.12$,

Table 1. Clinical characteristics of the study population. Patient characteristics ( $n=105$ patients)

\begin{tabular}{|c|c|c|}
\hline \multicolumn{2}{|c|}{ Age, years } & $72.1 \pm 10.1$ \\
\hline \multicolumn{2}{|l|}{ Male } & 77 (74.0\%) \\
\hline \multicolumn{2}{|c|}{ BMI, kg/m² } & $23.9 \pm 4.0$ \\
\hline \multirow{4}{*}{$\begin{array}{l}\text { Risk } \\
\text { factors }\end{array}$} & Hypertension & $63(60.0 \%)$ \\
\hline & Diabetes & 43 (41.0\%) \\
\hline & Dyslipidaemia & 66 (62.9\%) \\
\hline & Active smoking & 20 (19.0\%) \\
\hline
\end{tabular}

Medication (current user)

\begin{tabular}{|l|c|}
\hline Aspirin & $73(69.5 \%)$ \\
\hline Clopidogrel & $59(56.2 \%)$ \\
\hline Beta-blockers & $33(31.4 \%)$ \\
\hline RAAS antagonist & $42(40.0 \%)$ \\
\hline Calcium channel blockers & $32(30.5 \%)$ \\
\hline Statins & $53(50.5 \%)$ \\
\hline Clinical features & $66(62.9 \%)$ \\
\hline Stable angina & $23(21.9 \%)$ \\
\hline ACS &
\end{tabular}

Angiographic characteristics ( $n=137$ lesions)

Lesion characteristics

\begin{tabular}{|l|c|}
\hline Multivessel disease, $\mathrm{n} \mathrm{( \% )}$ & $33(31 \%)$ \\
\hline \%DS & $69.8 \pm 15.7 \%$ \\
\hline Prior MI-culprit lesion, $\mathrm{n}(\%)$ & $15(10.9 \%)$ \\
\hline Prior MI-remote lesion, $\mathrm{n}(\%)$ & $21(15.3 \%)$ \\
\hline Previous PCI lesion, $\mathrm{n}(\%)$ & $54(39.4 \%)$ \\
\hline Restenosis lesion, $\mathrm{n}(\%)$ & $10(7.3 \%)$ \\
\hline
\end{tabular}

Lesion distribution and DS

Branch, n (\%)

All, 137

LAD 76 (55.5\%)

RCA $36(26.3 \%)$

LCX 26 (18.2\%)

ACS: acute coronary syndrome; BMI: body mass index; DS: diameter stenosis; LAD: left anterior descending artery; LCX: left circumflex artery; $\mathrm{MI}$ : myocardial infarction; ns: not significant; $\mathrm{PCl}$ : percutaneous coronary intervention; RAAS: renin-angiotensin-aldosterone system; RCA: right coronary artery

respectively $(\mathrm{p}<0.001)$. The mean value of FFR was $0.80 \pm 0.13$ $(\mathrm{p}<0.0001$ vs. SPR-5 and SPR-3). There were strong correlations between SPR-5 or SPR-3 and FFR $(\mathrm{R}=0.941, \mathrm{p}<0.001$, and $\mathrm{R}=0.933, \mathrm{p}<0.001$, respectively) (Figure 2A, Figure 2B). We found a strong correlation between SPR-5 and SPR-3 $(R=0.987, p<0.0001)$ and a close agreement on Bland-Altman analysis (bias: $0.01 \pm 0.005$, 95\% CI of disagreement: $-0.03-0.05$ ) (Figure 2C). ROC curve analysis using SPR-5 and FFR values is shown in Figure 3. The SPR-5 cut-off value for predicting FFR $\leq 0.80$ was 0.84 . The AUC was 0.96 (95\% CI: $0.90-0.99$, specificity 94.3 , sensitivity 79.9). PPV was $92.3 \%$ and NPV was $82.3 \%$. The diagnostic accuracy was $86.3 \%$. 

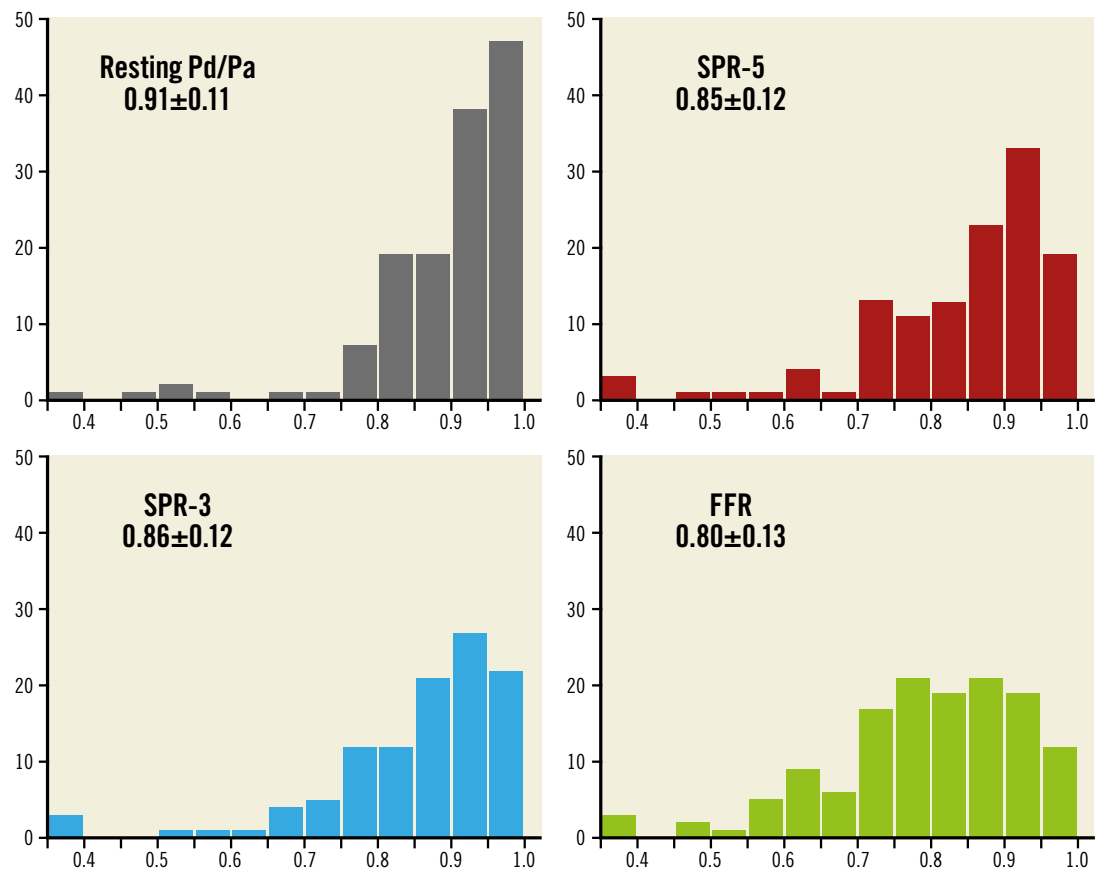

Figure 1. Distribution of pressure measurements in all patients.

The grey zone included SPR-5 values in the range 0.830.88 (Table 2) (33 lesions [24\%]). The hybrid approach using SPR-5 and FFR showed excellent accuracy (96\%) for predicting FFR $\leq 0.80$.

A representative case is shown in Figure 4. In SPR-5 and SPR-3 (Figure 4A, Figure 4B), resting $\mathrm{Pa}$ was $98 \mathrm{mmHg}$ in SPR-5 and $97 \mathrm{mmHg}$ in SPR-3 (red line). Three heartbeats after starting saline injection, the $\mathrm{Pd}$ value began to decrease rapidly from 84 to $76 \mathrm{mmHg}$ in SPR-5 and from 83 to $78 \mathrm{mmHg}$ in SPR-3, before reaching a plateau. Subsequently, it gradually returned to baseline (green line). The $\mathrm{Pd} / \mathrm{Pa}$ value showed a rapid decrease and subsequent increase, followed by a plateau and gradual return to baseline (yellow line). SPR-5 was 0.78 and SPR-3 was 0.79 (arrows). In $\mathrm{FFR}+$ saline (Figure $4 \mathrm{C}$ ), the $\mathrm{Pd} / \mathrm{Pa}$ value directly returned to baseline.

Table 2. Criterion values and coordinates of the ROC curve for SPR-5.

\begin{tabular}{|l|c|c|c|c|}
\hline Criterion & Sensitivity & $95 \%$ CI & Specificity & $95 \%$ CI \\
\hline$<0.33$ & 0.00 & $0.0-5.9$ & 100.00 & $94.9-100.0$ \\
\hline$\leq 0.82$ & 63.93 & $50.6-75.8$ & 100.00 & $94.9-100.0$ \\
\hline$\leq 0.83$ & 70.49 & $57.4-81.5$ & 97.14 & $90.1-99.7$ \\
\hline$\leq 0.84$ & 78.69 & $66.3-88.1$ & 94.29 & $86.0-98.4$ \\
\hline$\leq 0.85$ & 81.97 & $70.0-90.6$ & 90.00 & $80.5-95.9$ \\
\hline$\leq 0.86$ & 86.89 & $75.8-94.2$ & 82.86 & $72.0-90.8$ \\
\hline$\leq 0.87$ & 88.52 & $77.8-95.3$ & 81.43 & $70.3-89.7$ \\
\hline$\leq 0.88$ & 95.08 & $86.3-99.0$ & 80.00 & $68.7-88.6$ \\
\hline$\leq 0.89$ & 96.72 & $88.7-99.6$ & 78.57 & $67.1-87.5$ \\
\hline$\leq 0.90$ & 98.36 & $91.2-100.0$ & 71.43 & $59.4-81.6$ \\
\hline$\leq 0.91$ & 100.00 & $94.1-100.0$ & 64.29 & $51.9-75.4$ \\
\hline$\leq 1$ & 100.00 & $94.1-100.0$ & 0.00 & $0.0-5.1$ \\
\hline
\end{tabular}
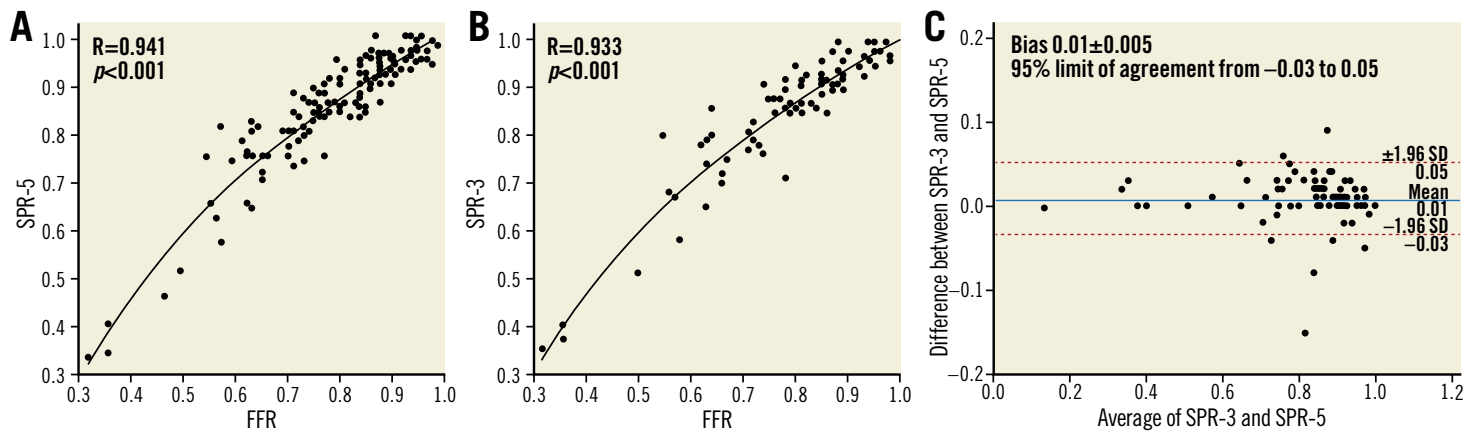

Figure 2. Relationship between SPR and FFR values. A) SPR-5. B) SPR-3. Correlations were similar and good. C) Bland-Altman plot demonstrated close agreement between SPR-5 and SPR-3 (0.01 $\pm 0.005,95 \%$ CI of disagreement: -0.03-0.05). CI: confidence interval; FFR: fractional flow reserve; SPR-5, SPR-3: saline-induced Pd/Pa ratio for five and three heartbeats, respectively 


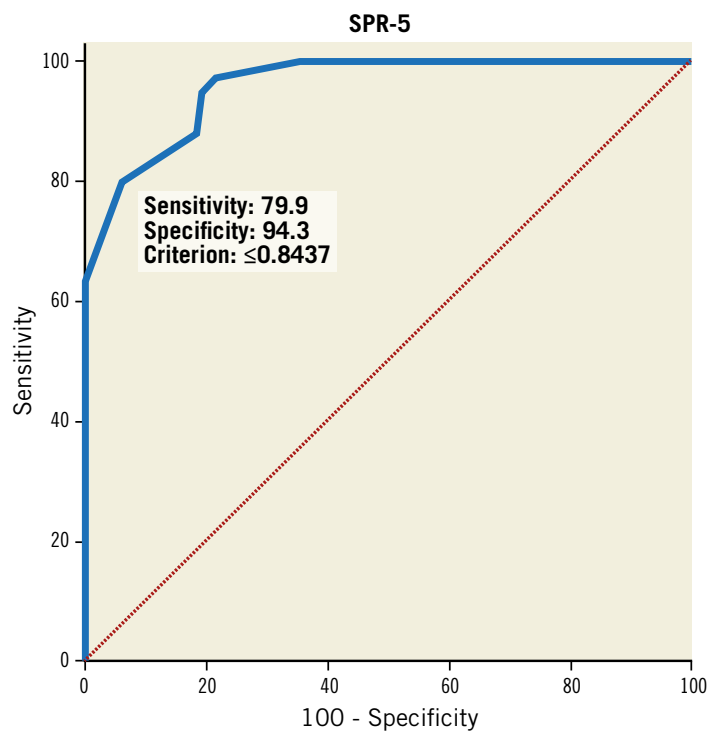

Figure 3. Receiver operating characteristic curve analysis. AUC demonstrated good accuracy of an SPR-5 cut-off of $\leq 0.84$ for predicting FFR $\leq 0.80$ (AUC 0.96 [95\% CI: 0.90-0.99, specificity 93.0, sensitivity 79.2]). AUC: area under the curve; CI: confidence interval; SPR-5: saline-induced $P d / P$ a ratio for five heartbeats

FFR and FFR+saline were strongly correlated $(\mathrm{R}=0.989$, $\mathrm{p}<0.0001$ ) (Figure 5), with close agreement between the two indices on Bland-Altman analysis $(0.001 \pm 0.004,95 \%$ CI of disagreement: $-0.04-0.04)$. There was a greater difference between SPR-5 and FFR (SPR-FFR) in lesions with higher resting $\mathrm{Pd} / \mathrm{Pa}$ than in lesions with lower resting $\mathrm{Pd} / \mathrm{Pa}$ (Figure 6).

\section{INFLUENCE OF CATHETER SIZE ON SPR AND REPRODUCIBILITY OF SALINE INJECTION}

We used $4 \mathrm{Fr}$ and $5 \mathrm{Fr}$ diagnostic catheters in 78 and 11 lesions, respectively, and 6 Fr guiding catheters in 48 lesions. SPR-5 and FFR were strongly correlated in the 4 and 5 Fr diagnostic catheter group ( $\mathrm{n}=89, \mathrm{R}=0.908$ ). There was also a strong correlation in the $6 \mathrm{Fr}$ guiding catheter group $(\mathrm{R}=0.952)$. The ICCs showed absolute agreement between the first and second SPR measurements at a high level (ICC $=0.996$ [95\% CI: 0.994, 0.998], $\mathrm{p}<0.0001)$.

\section{COMPLICATIONS}

In 673 SPR assessments, no complications were observed. In contrast, during FFR assessments, nearly $20 \%$ of patients complained of chest discomfort and one experienced severe hypotension.

\section{Discussion}

SPR assessment requires only a single intracoronary saline bolus. The results of this study demonstrated high accuracy of SPR for predicting the functional significance of coronary stenosis assessed by FFR in lesions excluding tandem stenosis. We found an excellent agreement between SPR-5 and SPR-3, a lower mean value and a slightly better correlation with FFR for SPR-5 than for SPR-3. The interval before returning to baseline in both $\mathrm{Pd}$ and $\mathrm{Pd} /$ Pa values was 10\%-20\% longer for SPR-5 than for SPR-3. These

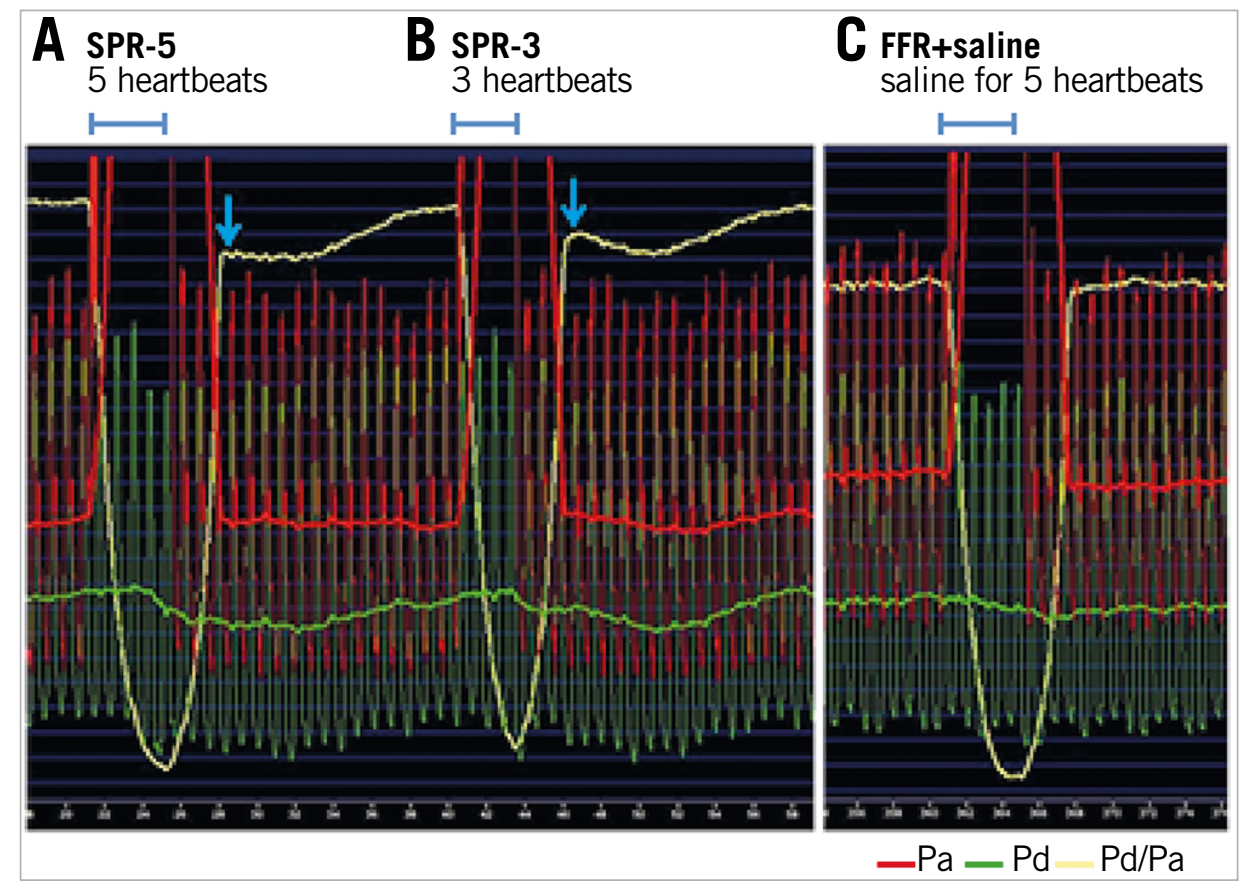

Figure 4. $P d / P$ a records from a 76-year-old woman with stable angina. A) SPR-5 was 0.73 (arrow). B) SPR-3 was 0.79 (arrow). C) Additional intracoronary saline injection during FFR assessment (FFR+saline) did not affect the FFR value. FFR: fractional flow reserve; SPR-5, $S P R$-3: saline-induced Pd/Pa ratio for five heartbeats and three heartbeats, respectively 

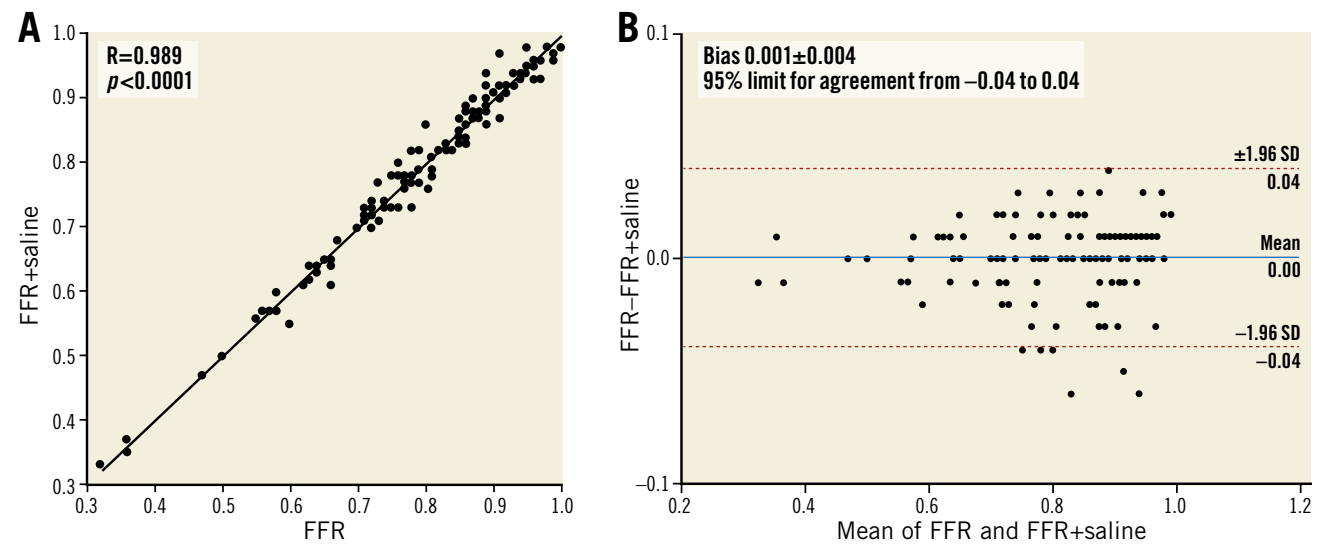

Figure 5. Relationship between FFR and FFR+saline. A) Excellent correlation between FFR and FFR+saline was observed. B) Bland-Altman plot demonstrated a close agreement between FFR and FFR + saline (0.001 \pm 0.004 , 95\% CI of disagreement: -0.04-0.04), suggesting additional saline injection did not affect FFR values. CI: confidence interval; FFR: fractional flow reserve; FFR + saline: additional saline injection during FFR recording

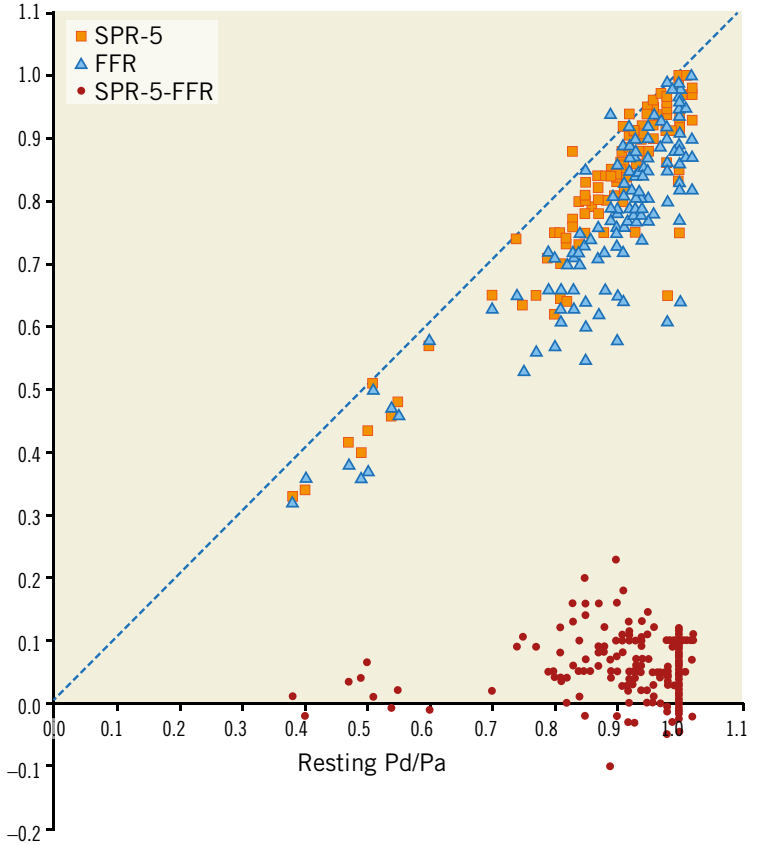

Figure 6. Relationship between resting Pd/Pa and SPR-5, FFR and (SPR-5 - FFR). SPR-5 - FFR values are obviously larger in the lesions with higher resting $P d / P a$ than in the lesions with lower resting Pd/Pa. FFR: fractional flow reserve; $S P R-5$ : saline-induced $P d / P$ a ratio for five heartbeats; SPR-5 - FFR: difference between SPR-5 and FFR

differences might be due to more heartbeats of saline streaming through the arterioles and complete replacement of blood with saline in SPR-5. Hence, SPR-5 is more appropriate for assessment.

\section{MECHANISM OF SPR}

The potential mechanisms of increase in coronary flow induced by intracoronary saline administration still remain unclear. De Bruyne et al demonstrated increases of epicardial coronary flow velocity by continuous intracoronary saline infusion $(\sim 20 \mathrm{~mL} /$ minute) in patients free of stenosis ${ }^{17}$. They proposed mechanisms of hyperaemia induced by continuous saline infusion, such as temperature of saline, decreased local arterial oxygen content, myocardial ischaemia, or endothelial paracrine pathways. In their study, the decrease in Pd value began 20 seconds after starting the saline infusion. This implies that hyperaemia appeared within $\sim 20$ seconds from starting saline infusion in non-stenotic coronary arteries. In our study, saline injection $(2 \mathrm{~mL} / \mathrm{sec})$ in a coronary artery with a stenotic lesion caused the Pd value to decrease within only three to four heartbeats (Figure 4). Saline mainly streams through the epicardial coronary artery during this initial period of three to four heartbeats after starting saline injection, and subsequently begins to stream through the arterioles. Therefore, Pd decreases seem to appear too soon and are too rapid to be explained by hyperaemia.

From these findings, we speculate that the low viscosity effect is the most probable mechanism of SPR. When saline begins to stream through the arterioles (second period), the viscosity begins to decrease rapidly in the arterioles and the Pd value immediately begins to decrease rapidly. When saline continues to stream through the arterioles (third period), viscosity stays at the minimum and the Pd value plateaus. When saline is gradually replaced with blood again (fourth period), viscosity increases gradually and the $\mathrm{Pd}$ value gradually returns to baseline. During the third and fourth periods, the $\mathrm{Pd} / \mathrm{Pa}$ value plateaus and is followed by a gradual return to baseline. As an additional mechanism, it is possible that hyperaemia induced by saline injection appears in the mid to late phase of the process, earlier than reported in the study by De Bruyne et al because saline was injected at a higher flow rate in our study. The appearance of reactive vasodilation in the third period might be one of the reasons for the gradual return of $\mathrm{Pd}$ value to baseline.

Temporary decreases in $\mathrm{Pd}$ and $\mathrm{Pd} / \mathrm{Pa}$ were seen during the third period in 13 SPR assessments (eight SPR-5s and five SPR-3s), 
especially when repeating saline injections within a short interval (Figure 4A, Figure 4B). Most accompanied a temporary decrease in systemic blood pressure. De Bruyne et al demonstrated no effect of intracoronary saline infusion $(\sim 20 \mathrm{~mL} / \mathrm{min})$ on left ventricular function in patients without coronary stenosis ${ }^{18}$. However, we speculate that, in patients with coronary stenosis, temporary myocardial ischaemia enhanced by intracoronary saline injection followed by a short interval may depress ventricular function, resulting in temporary decreases of $\mathrm{Pa}$ and $\mathrm{Pd}$ values. Therefore, the inflection point is considered adequate as an SPR value to avoid this.

Additional intracoronary boluses of saline (FFR+saline) did not affect FFR values (Figure 5), suggesting that the low viscosity effect does not appear under the condition of maximally dilated arterioles.

\section{LIMITATIONS OF CURRENT ASSESSMENT METHODS}

Despite the importance of patient outcome demonstrated by the FFR study ${ }^{18}$, FFR has remained underused because of the need for adenosine and procedural inconvenience ${ }^{5,6}$. Additionally, the issue of insufficient arteriolar dilation by adenosine remains unsolved. A simpler method that can easily predict FFR $\leq 0.80$ would be useful for the widespread application of FFR. Leone et al demonstrated a high accuracy $(89 \%)$ of cFFR for predicting FFR $\leq 0.80$ using multiple contrast media ${ }^{9}$, and Johnson et al also reported the high accuracy (83.5\%) of cFFR using eight different contrast media ${ }^{10}$. However, the heterogeneity among different contrast media was not examined in either study. Furthermore, cFFR requires more additional doses of contrast medium to assess multiple lesions. These disadvantages would limit its widespread application. In contrast, although iFR and resting $\mathrm{Pd} / \mathrm{Pa}$ are simple methods that do not require agents and have shown patient outcomes in large patient populations ${ }^{1,2}$, both assessments have an accuracy of around $80 \%$ for predicting FFR $\leq 0.80^{19}$.

\section{ACCURACY AND UTILITY OF SPR}

We demonstrated high accuracy (86.3\%) of SPR-5 for predicting FFR $\leq 0.80$. The grey zone of SPR included $24 \%$ of lesions, almost identical to the $22 \%$ seen with cFFR (adenosine zone) ${ }^{9}$. Using SPR, the use of adenosine for FFR assessment is limited to one in four lesions. SPR assessment does not require any vasodilator agent or contrast medium and has advantages, such as its simplicity, low cost, speed, easy repeatability, and safety. Since one SPR measurement requires 6 to $10 \mathrm{~mL}$ of saline and only 20 heartbeats, we can repeat measurements sequentially several times if needed. Furthermore, we can use SPR for assessing multiple lesions without being concerned about the dose of contrast medium or the time needed for assessments. More importantly, SPR data are applicable around the world.

Finally, SPR reflects not only the ability of stenotic coronary lesions to supply blood but also the basal condition of arteriolar dilation induced by myocardial ischaemia if the primary mechanism is a low viscosity effect. In contrast, arterioles are maximally dilated by adenosine for FFR assessment. In this study, we demonstrated excellent agreement between FFR and FFR+saline (Figure 5) and obviously larger differences between SPR and FFR values (SPR-FFR) in the lesions with higher resting $\mathrm{Pd} / \mathrm{Pa}$ than in the lesions with lower resting $\mathrm{Pd} / \mathrm{Pa}$ (Figure 6). These two findings imply that arterioles distal to the stenotic lesions are dilated proportionally in response to basal myocardial ischaemia. It is possible that combined assessment of SPR and FFR has the potential to characterise the microcirculatory condition in acute coronary syndrome. Furthermore, it is possible that arteriolar dilation induced by adenosine for FFR assessment might be insufficient when SPR-FFR is a small or negative value. We expect the combined assessment of SPR and FFR to be useful to detect these insufficient assessments using adenosine.

\section{Study limitations}

We excluded patients with extreme bradycardia because of the possibility of ventricular arrhythmia. Therefore, SPR-3 might be safer for these patients. We also excluded patients with ostial stenosis because it would require much more saline for complete replacement, leading to severe depression of left ventricular function or dangerous arrhythmia. SPR assessment cannot perform pullback evaluation due to the short-term effect of saline. Finally, and most importantly, since the size of our patient population was quite small, further studies are needed to confirm the validity of SPR. We expect that studies with a larger population including tandem lesions could provide useful information in order to understand the basal condition of arterioles induced by the combination of multiple lesions.

\section{Conclusions}

SPR is a novel method without any agents based on the speculated low viscosity effect. It is a simple, easy-to-use, safe, and useful method for predicting the functional significance of coronary stenosis assessed by FFR, with high reliability and easy repeatability. Using SPR, we can easily apply the results from previous studies indicating patient outcomes and limit the use of adenosine for FFR assessment to one in four lesions.

\section{Impact on daily practice}

To apply the results from previous FFR studies in clinical practice, SPR can easily and accurately predict FFR. SPR needs no vasodilators or contrast medium and requires $\leq 10 \mathrm{~mL}$ of saline and 20 heartbeats. Using SPR, we can limit the need for adenosine for FFR to one in four lesions.

\section{Acknowledgements}

We would like to thank Editage (www.editage.com) for English language editing and publication support.

\section{Conflict of interest statement}

The authors have no conflicts of interest to declare. 


\section{References}

1. Götberg M, Christiansen EH, Gudmundsdottir IJ, Sandhall L, Danielewicz M, Jakobsen L, Olsson SE, Öhagen P, Olsson H, Omerovic E, Calais F, Lindroos P, Maeng M, Tödt T, Venetsanos D, James SK, Kåregren A, Nilsson M, Carlsson J, Hauer D, Jensen J, Karlsson AC, Panayi G, Erlinge D, Fröbert O; iFR-SWEDEHEART Investigators. Instantaneous Wave-free Ratio versus Fractional Flow Reserve to Guide PCI. $N$ Engl $J$ Med. 2017;376:1813-23.

2. Davies JE, Sen S, Dehbi HM, Al-Lamee R, Petraco R, Nijjer SS, Bhindi R, Lehman SJ, Walters D, Sapontis J, Janssens L, Vrints CJ, Khashaba A, Laine M, Van Belle E, Krackhardt F, Bojara W, Going O, Härle T, Indolfi C, Niccoli G, Ribichini F, Tanaka N, Yokoi H, Takashima H, Kikuta Y, Erglis A, Vinhas H, Canas Silva P, Baptista SB, Alghamdi A, Hellig F, Koo BK, Nam CW, Shin ES, Doh JH, Brugaletta S, Alegria-Barrero E, Meuwissen M, Piek JJ, van Royen N, Sezer M, Di Mario C, Gerber RT, Malik IS, Sharp ASP, Talwar S, Tang K, Samady H, Altman J, Seto AH, Singh J, Jeremias A, Matsuo H, Kharbanda RK, Patel MR, Serruys P, Escaned J. Use of the Instantaneous Wave-free Ratio or Fractional Flow Reserve in PCI. N Engl J Med. 2017;376: 1824-34.

3. Levine GN, Bates ER, Blankenship JC, Bailey SR, Bittl JA, Cercek B, Chambers CE, Ellis SG, Guyton RA, Hollenberg SM, Khot UN, Lange RA, Mauri L, Mehran R, Moussa ID, Mukherjee D, Nallamothu BK, Ting HH. 2011 ACCF/AHA/SCAI Guideline for Percutaneous Coronary Intervention: Executive Summary. A Report of the American College of Cardiology Foundation/American Heart Association Task Force on Practice Guidelines and the Society for Cardiovascular Angiography and Interventions. Circulation. 2011; 124:2574-609.

4. Task Force Members, Montalescot G, Sechtem U, Achenbach S, Andreotti F, Arden C, Budaj A, Bugiardini R, Crea F, Cuisset T, Di Mario C, Ferreira JR, Gersh BJ, Gitt AK, Hulot JS, Marx N, Opie LH, Pfisterer M, Prescott E, Ruschitzka F, Sabaté M, Senior R, Taggart DP, van der Wall EE, Vrints CJ; ESC Committee for Practice Guidelines, Zamorano JL, Achenbach S, Baumgartner H, Bax JJ, Bueno H, Dean V, Deaton C, Erol C, Fagard R, Ferrari R, Hasdai D, Hoes AW, Kirchhof P, Knuuti J, Kolh P, Lancellotti P, Linhart A, Nihoyannopoulos P, Piepoli MF, Ponikowski P, Sirnes PA, Tamargo JL, Tendera M, Torbicki A, Wijns W, Windecker S; Document Reviewers, Knuuti J, Valgimigli M, Bueno H, Claeys MJ, Donner-Banzhoff N, Erol C, Frank H, FunckBrentano C, Gaemperli O, Gonzalez-Juanatey JR, Hamilos M, Hasdai D, Husted S, James SK, Kervinen K, Kolh P, Kristensen SD, Lancellotti P, Maggioni AP, Piepoli MF, Pries AR, Romeo F, Rydén L, Simoons ML, Sirnes PA, Steg PG, Timmis A, Wijns W, Windecker S, Yildirir A, Zamorano JL. 2013 ESC guidelines on the management of stable coronary artery disease: the Task Force on the management of stable coronary artery disease of the European Society of Cardiology. Eur Heart J. 2013;34:2949-3003.

5. Pijls NH, De Bruyne B. Coronary pressure measurement and fractional flow reserve. Heart. 1998;80:539-42.
6. Wilson RF, Wyche K, Christensen BV, Zimmer S, Laxson DD. Effects of adenosine on human coronary arterial circulation. Circulation. 1990;82:1595-606.

7. Leone AM, Porto I, De Caterina AR, Basile E, Aurelio A, Gardi A, Russo D, Laezza D, Niccoli G, Burzotta F, Trani C, Mazzari MA, Mongiardo R, Rebuzzi AG, Crea F. Maximal hyperemia in the assessment of fractional flow reserve: intracoronary adenosine versus intracoronary sodium nitroprusside versus intravenous adenosine: the NASCI (Nitroprussiato versus Adenosina nelle Stenosi Coronariche Intermedie) study. JACC Cardiovasc Interv. 2012;5:402-8.

8. Pijis NH, Tonino PA. The crux of maximal hyperemia: the last remaining barrier for routine use of fractional flow reserve. JACC Cardiovasc Interv. 2014;4:1093-5.

9. Leone AM, Martin-Reyes R, Baptista SB, Amabile N, Raposo L, Franco Pelaez JA, Trani C, Cialdella P, Basile E, Zimbardo G, Burzotta F, Porto I, Aurigemma C, Rebuzzi AG, Faustino M, Niccoli G, Abreu PF, Slama MS, Spagnoli V, Telleria Arrieta M, Amat Santos IJ, de la Torre Hernandez JM, Lopez Palop R, Crea F. The Multi-center Evaluation of the Accuracy of the Contrast Medium Induced $\mathrm{Pd} / \mathrm{Pa} \mathrm{RaTiO}$ in Predicting FFR (MEMENTO-FFR) Study, EuroIntervention. 2016;12:708-15.

10. Johnson NP, Jeremias A, Zimmermann FM, Adjedj J, Witt N, Hennigan B, Koo BK, Maehara A, Matsumura M, Barbato E, Esposito G, Trimarco B, Rioufol G, Park SJ, Yang HM, Baptista SB, Chrysant GS, Leone AM, Berry C, De Bruyne B, Gould KL, Kirkeeide RL, Oldroyd KG, Pijls NHJ, Fearon WF. Continuum of Vasodilator Stress From Rest to Contrast Medium to Adenosine Hyperemia for Fractional Flow Reserve Assessment. JACC Cardiovasc Interv. 2016;9:757-67.

11. Baile EM, Paré PD, D’yachkova, Carere RG. Effect of contrast media on coronary vascular resistance: contrast-induced coronary vasodilation. Chest. 1999;116:1039-45.

12. Charm SE, Kurland GS. Blood rheology. In: Bergel DH, editor. Cardiovascular Fluid Dynamics, Vol. 2. London: Academic Press; 1972. p. 57-203.

13. Shiga T, Maeda N, Kon K. Erythrocyte rheology. Crit Rev Oncol Hematol. 1990;10:9-48.

14. Soutani M, Suzuki Y, Tateishi N, Maeda N. Quantitative evaluation of flow dynamics of erythrocytes in microvessels: influence of erythrocyte aggregation. Am J Physiol. 1995;268:H1959-65.

15. Wells R. Syndromes of hyperviscosity. $N$ Engl J Med. 1970;283:183-6.

16. Sutera SP, Skalak R. The history of Poiseuille's law. Annu Rev Fluid Mech. 1993;25:1-20.

17. De Bruyne B, Adjedj J, Xaplanteris P, Ferrara A, Mo Y, Penicka M, Floré V, Pellicano M, Toth G, Barbato E, Duncker DJ, Pijls NH. Saline-Induced Coronary Hyperemia. Mechanisms and Effects on Left Ventricular Function. Circ Cardiovasc Interv. 2017 Apr;10(4)

18. De Bruyne B, Pijls NH, Kalesan B, Barbato E, Tonino PA, Piroth Z, Jagic N, Möbius-Winker S, Rioufol G, Witt N, Kala P, MacCarthy $\mathrm{P}$, Engström $\mathrm{T}$, Oldroyd KG, Mavromatis $\mathrm{K}$, 
Manoharan G, Verlee P, Frobert O, Curzen N, Johnson JB, Jüni P, Fearon WF; FAME 2 Trial Investigators. Fractional flow reserveguided PCI versus medical therapy in stable coronary disease. N Engl J Med. 2012;367:991-1001.

19. Jeremias A, Maehara A, Généreux P, Asrress KN, Berry C, De Bruyne B, Davies JE, Escaned J, Fearon WF, Gould KL,
Johnson NP, Kirtane AJ, Koo BK, Marques KM, Nijjer S, Oldroyd KG, Petraco R, Piek JJ, Pijls NH, Redwood S, Siebes M, Spaan JA, van't Veer M, Mintz GS, Stone GW. Multicenter core laboratory comparison of the instantaneous wave-free ratio and resting $\mathrm{Pd} / \mathrm{Pa}$ with fractional flow reserve: the RESOLVE study. J Am Coll Cardiol. 2014;63:1253-61. 